This is the peer reviewed version of the following article: Leivesley, J. A., Bussière, L. F., Pemberton, J. M., Pilkington, J. G., Wilson, K. and Hayward, A. D. (2019), Survival costs of reproduction are mediated by parasite infection in wild Soay sheep. Ecol Lett, 22: 1203-1213, which has been published in final form at https://doi.org/10.1111/ele.13275. This article may be used for non-commercial purposes in accordance with Wiley Terms and Conditions for self-archiving.

\title{
Survival costs of reproduction are mediated by parasite infection in wild
}

\section{Soay sheep}

Jessica A. Leivesley ${ }^{1,2}$, Luc F. Bussière ${ }^{1}$, Josephine M. Pemberton ${ }^{3}$, Jill G. Pilkington ${ }^{3,4}$, Kenneth Wilson ${ }^{5} \&$ Adam D. Hayward $^{1,6}$

1. Department of Biological and Environmental Sciences, University of Stirling, Stirling, FK9 4LA, UK. Email: luc.bussiere@stir.ac.uk

2. Current address: Department of Ecology and Evolutionary Biology, University of Toronto, Toronto, M5S 3B2, Canada. Email: jessica.leivesley@ mail.utoronto.ca

3. Institute of Evolutionary Biology, University of Edinburgh, Ashworth Laboratories, Charlotte Auerbach Road, Edinburgh, EH9 3FL, UK. Email: j.pemberton@ed.ac.uk

4. School of Biology, University of St Andrews, Sir Harold Mitchell Building, St Andrews, KY16 9TF, UK. Email: jgp8@st-andrews.ac.uk

5. Lancaster Environment Centre, Lancaster University, Lancaster, LA1 4YQ, UK. Email: ken.wilson@lancaster.ac.uk

6. Current address: Moredun Research Institute, Pentland Science Park, Penicuik, Midlothian, EH26 0PZ. Email: adam.hayward@moredun.ac.uk

Statement of authorship: JAL and ADH designed the study; JAL performed all statistical analyses after discussion with ADH and LFB; JGP and KW made significant contributions to collection of parasitology data across the history of the Soay sheep project, which is directed by JMP; JAL wrote the first draft of the manuscript and LFB, JMP, KW and ADH contributed substantially to revisions.

Data accessibility statement: Should the manuscript be accepted for publication, the data supporting the results will be archived in the Dryad data repository under a DOI, which will be included at the end of the article.

Running title: Parasite-mediated reproductive costs 
Keywords: Life history; infection; immunity; trade-offs; fitness; peri-parturient rise; costs of reproduction

Type of article: Letters

Word Count: Abstract $=150$ Main text $=4999$

References: 82

Figures: 3

Tables: 2

Text boxes: 0

Corresponding author: Adam Hayward, Moredun Research Institute, Pentland Science

Park, Penicuik, Midlothian, EH26 0PZ. Email: adam.hayward @ moredun.ac.uk; Tel: +44 (0) 1314455111. 


\section{$1 \underline{\text { Abstract }}$}

2 A trade-off between current and future fitness potentially explains variation in life-history 3 strategies. A proposed mechanism behind this is parasite-mediated reproductive costs: 4 individuals that allocate more resources to reproduction have fewer to allocate to defence 5 against parasites, reducing future fitness. We examined how reproduction influenced faecal 6 egg counts (FEC) of strongyle nematodes using data collected between 1989-2008 from a wild 7 population of Soay sheep in the St. Kilda archipelago, Scotland (741 individuals). Increased 8 reproduction was associated with increased FEC during the lambing season: females that gave

9 birth, and particularly those that weaned a lamb, had higher FEC than females that failed to 10 reproduce. Structural equation modelling revealed future reproductive costs: a positive effect 11 of reproduction on spring FEC and a negative effect on summer body weight were negatively associated with overwinter survival. Overall, we provide evidence that parasite resistance and body weight are important mediators of survival costs of reproduction. 
27 Life-history theory is dominated by the principle that reproduction is associated with large resource costs, meaning individuals constantly face trade-offs, such as that between current and future reproduction (Williams 1966). Theory predicts that current reproduction is expected to reduce future survival because individuals command finite resources, which they must apportion between life-history characteristics (Stearns 1992). The term 'investment' implies direct future fitness costs of provisioning resources to a characteristic, whereas the term 'allocation' does not imply any direct fitness cost (Hamel et al. 2010). The theory of parasitemediated reproductive costs specifies that resource allocation trade-offs between reproduction and immunity are central to regulating the reproduction-survival trade-off, because increased allocation of resources to reproduction should suppress allocation of resources to immunity and reduce future survival (Sheldon \& Verhulst 1996).

Both observational and experimental studies have provided support for a trade-off between reproduction and parasite resistance (Festa-Bianchet 1989; Richner et al. 1995; Ardia et al. 2003; Pelletier et al. 2005; Graham et al. 2010; Mills et al. 2010). Despite this, to support the hypothesis of parasite-mediated reproductive costs in an observational study we must also demonstrate that reduced parasite resistance is associated with reduced future fitness. Experimental removal of parasites in wild populations has been shown to increase survival (Gulland 1992; la Puente et al. 2010; Watson 2013), suggesting increased parasite burdens may mediate effects of reproduction on survival. However, detecting trade-offs in observational studies can be difficult due to differences in resource acquisition between individuals (van Noordwijk \& de Jong 1986). These differences may mean that some individuals have resources available to allocate to both reproduction and immunity, while others may struggle to allocate 
exist. The costs of reproduction are also likely dependent on age and sex (e.g. Descamps et al. 2009). In mammals, while there are costs of bearing offspring, the greatest costs are often attributed to lactation (Clutton-Brock et al. 1989; Froy et al. 2016).

Long-term, individual-based studies in natural systems are critical to testing life-history theory, but are rare as they are difficult to maintain (Lindenmayer et al. 2012). Here, we quantified the pathways linking reproduction, parasite egg counts, body weight, and survival using 19 years of data collected from a wild population of Soay sheep (Ovis aries). Many parasite species are present, but gastrointestinal strongyle nematodes have the greatest effect on health and mortality of any parasite in the population and are highly prevalent (Gulland 1992; Gulland \& Fox 1992). Strongyles have a direct life cycle: adults live up to 60 days in the host (Armour et al. 1966), producing eggs that are shed in faeces; eggs hatch and moult to L3 larvae that are ingested by sheep during grazing. Infection intensity of strongyles is quantified with faecal egg count (FEC), which is strongly positively correlated with worm burden (Wilson et al. 2004).

65

66 Survival of female Soay sheep reproducing in spring (mean survival $=90.8 \%$ ) is lower than non-reproducing females (95.5\%) over the subsequent winter (Clutton-Brock et al. 1996; Tavecchia et al. 2005). This difference is more pronounced in years of harsh winters (CluttonBrock et al. 1996). Two observations suggest that parasites could mediate this reproductionsurvival association. First, a rise in FEC occurs during late pregnancy and early lactation in this population (Tempest 2005), a phenomenon known as the peri-parturient rise (Lloyd 1983;

72 Fthenakis et al. 2015). Second, higher FEC and lower body weight are associated with lower overwinter survival (Clutton-Brock et al. 1992; Gulland 1992; Hayward et al. 2011, 2018). We therefore evaluated whether allocation to reproduction incurred survival costs mediated by its 
effect on FEC and body weight. Our results support the notion that costs of reproduction, manifested as reduced survival, are mediated by both strongyle FEC and body weight.

\section{Material and methods}

\section{Study Population and Data Collection}

The St. Kilda archipelago (54 $49^{\prime} 08^{\circ} 34^{\prime}$ W) lies $65 \mathrm{~km}$ west of the Outer Hebrides, Scotland, and consists of four islands: Hirta, Soay, Boreray, and Dun. A population of unmanaged Soay sheep, descendants of primitive European domestic sheep that were introduced to the island of Soay several thousand years ago (Clutton-Brock \& Pemberton 2004), inhabit the island of Hirta. Population dynamics on Hirta are characterised by periods of growth followed by large declines in population size due to adverse winter weather, poor food availability, and parasite infections, which combine to reduce body weight and increase mortality (Gulland 1992; Coulson et al. 2001; Craig et al. 2006).

A longitudinal individual-based study on the sheep in the Village Bay area of Hirta began in 1985 and continues to the present (Clutton-Brock \& Pemberton 2004). The population is monitored daily during the lambing season in March-May. $>95 \%$ of lambs are caught within a week of birth and are given an identification tag, weighed, and have blood and tissue samples taken. Throughout the history of the study, faecal samples have been collected from adults during lambing; often, the same individuals are repeatedly sampled within a year. Lambs suckle throughout the spring and are weaned by August. In August, around 50\% of the population are captured to collect a variety of measures including body weight and faecal samples.

\section{Change in FEC across lambing season}


99 We first determined how differences in reproductive allocation were associated with the PPR

100 in strongyle faecal egg count (FEC). Faecal samples were collected from both sexes across the

101 springs of $1989-2008$ ( $1^{\text {st }}$ March $-29^{\text {th }}$ May) and FEC was quantified using a modified version

102 of the McMaster technique (Craig et al. 2006). We constructed models assessing changes in

103 FEC during the lambing season including the following predictors.

104

105

Relative date: The date on which FEC samples were taken was standardised relative to the date

of lamb birth (lamb birth = day 0). Relative dates for non-reproducing females and males were based on the average lambing date for a given year. We analysed FEC data restricted to 49 days either side of lamb birth (relative date $=-49$ to +49 ). Our results and conclusions were unchanged if we also used year-specific mean lambing dates to calculate relative date for reproducing females, and if we used absolute date of sample collection for all individuals.

112 Reproductive status: Each year, females were divided into two categories: (0) did not 113 reproduce; (1) produced at least one lamb.

115 Litter size: A categorical variable in reproducing females each year: (1) a single lamb; (2) twin 116 lambs.

118 Litter survival: A categorical variable measured at the end of each August in reproducing

119 females: (1) both twins alive; (2) one twin alive; (3) both twins dead; (4) a singleton alive; (5)

120 a singleton dead.

122 Anthelminthic treatment: This distinguishes individuals that received an anthelminthic bolus

123 or drench as part of experimental treatments to remove parasites, which have been applied on 
124 several occasions throughout the history of the study (Gulland 1992; Gulland et al. 1993; Boyd 1999; Wilson et al. 2003; Tempest 2005). The treatment was applied either in the August before

126 lambing or in the spring of lambing and was considered a categorical variable: (0) no treatment

127 before lambing; (1) treatment before lambing. We included treatment in our models to account 128 for possible effects of treatment on FEC in our correlative study. The bolus releases 129 anthelmintic for several weeks; to be conservative about any long-lasting effects of treatment, 130 we considered animals given a bolus in either August or April as treated before lambing.

131 Exclusion of treated animals from our analysis did not substantially influence our conclusions.

133 FEC+100 was natural log-transformed before analysis to adhere to assumptions of residual 134 normality. Generalised additive mixed-effects models (GAMMs) were used to determine how 135 FEC changed during the lambing season and to determine how reproductive allocation was associated with the change in FEC. GAMMs allowed us to fit non-parametric smoothing

137 functions to FEC without being restricted to a specific polynomial form. Year and individual 138 identity were included in all models as random effects since multiple faecal samples were taken

139 from individuals within and across years. Analyses were performed in R 3.5.0 (R Core Team 140 2018) using the 'gamm4' package (Wood \& Scheipl 2017).

142 We performed separate analyses to model changes in FEC for different age groups: juveniles 143 (one year old in the spring of faecal sampling), yearlings (two years old), and adults (three or 144 more years), because these groups are known to differ in FEC (Wilson et al. 2004). We analysed 1129 FECs collected from 381 juveniles, 761 from 208 yearlings, and 2536 from 446 adults (Table S1). We tested associations between reproductive allocation and FEC in each age

147 group during the lambing season by grouping reproductive allocation in different ways based 148 on sex, reproductive status, litter size (adults only), and litter survival; the full list of models 
149 and groupings for each age class is shown in Tables S2-S4. Three models were compared for

150 each grouping where: (1) the intercept of FEC varied between the groups, but the change in

151 FEC across the season was consistent across groups; (2) the intercept of FEC was the same in

152 all groups, but the change in FEC across the season varied between groups; (3) both the

153 intercept of FEC and the change in FEC across the season varied between groups. In each

154 model, the anthelminthic treatment status of individuals was included as a fixed effect. All

155 models were compared using AIC values with the best-fitting model having the lowest AIC

156 value (Burnham \& Anderson 2002).

157

\section{Survival costs of reproduction}

159 We found that increased reproductive allocation in females was associated with higher FEC

160 during the spring (see Results). We next investigated how reproduction influenced female

161 survival, incorporating extensive prior knowledge about this system. Structural equation

162 models (SEMs) enabled us to test our a priori expectation that reproductive allocation has

163 effects on survival that are at least partly mediated by effects of reproduction on spring and

164 summer FEC and summer body weight. SEMs are well suited to testing the parasite-mediated

165 costs of reproduction because they specifically quantify the degree to which the relationship

166 between two variables is mediated by a third. SEMs were constructed using 601 records

167 collected from 325 females of all ages (many females are represented in more than one year),

168 including the following set of variables. All variables in the SEM were corrected for

169 anthelmintic treatment and age (see below). As recommended when evaluating SEMs (Grace

170 et al. 2014), our a priori path diagram (Fig. 1) is based on evidence for causal relationships

171 that might link reproduction and survival and known associations between traits in the Soay

172 sheep system (Table 1).

173 
174 Residual Spring FEC: Our GAMM analysis (see Results) was made possible by having

175 longitudinal FEC measures from the same individuals within years. However, for our SEMs,

176 we needed a single value of FEC per individual per year to pass to the model. Thus, we

177 extracted random effect estimates from a GAMM of $\operatorname{Ln}(\mathrm{FEC}+100)$ and included age (as a

178 three-level categorical variable: juvenile, yearling, adult), treatment, and relative date (as a

179 smoothed term) as explanatory variables. We summed the overall intercept, individual ID, and

180 year effect estimates to obtain a year-specific FEC value for every individual (year $t$ ),

181 accounting for variation in age, date, and treatment (i.e. the value represents the expected FEC

182 at day 0). This value was predicted to be positively associated with August FEC and negatively

183 associated with August body weight in year $t$ (Gulland 1992).

184

185

Reproductive status: Following our characterisation of the PPR in Soay sheep, females were grouped into two categories based on reproductive allocation: individuals either reproduced in year $t(\mathrm{n}=490)$ or did not $(\mathrm{n}=111)$. Of the reproducing female records, there were 89 records where no lambs survived. We chose to group females in this way, rather than based on lamb survival, since there was clear evidence for a different PPR in reproducing versus nonreproducing females (see Results). We predicted that reproductive status would be positively associated with residual spring FEC and negatively associated with August weight, since body weight is expected to reflect the allocation trade-off between reproduction and somatic maintenance (Clutton-Brock et al. 1996).

Population Density: We considered the effect of population density in the August before reproduction (year $t$-1) on reproductive status, since high density is associated with lower

197 fecundity (Clutton-Brock et al. 1991). We also considered the effect of density in year $t$ on 198 summer weight and FEC, and survival, since high density is associated with higher FEC 
199 (Gulland \& Fox 1992), lower summer body weight (Milner et al. 1999), and lower survival

200 (Clutton-Brock et al. 1991).

201

202 August FEC: We estimated summer strongyle FEC from samples taken during August captures

203 in year $t$. As above, to improve model fit and adhere to assumptions, FEC+100 estimates were

204 natural log-transformed. We expected this to be positively associated with spring FEC and negatively with August body weight (Coltman et al. 2001).

206

207

August Weight: Body weight was measured during August captures in year $t$ and was expected to be positively associated with survival (Clutton-Brock et al. 1996).

Overwinter survival: If the individual was observed during censuses conducted during May in

211 the following year $(t+1)$ the individual was considered to have survived the winter; resighting 212 probability of live individuals is close to $100 \%$. This was considered a categorical variable: (1) 213 survived to May $1^{\text {st}} ;(0)$ died before May $1^{\text {st }}$.

215 We used structural equation models (SEMs) to assess how reproduction was associated with

216 future survival in females and how this was mediated by FEC and body weight. We wanted to 217 estimate the partial effect of recent reproduction having controlled for age, and therefore 218 derived age-corrected measures of August body weight, August FEC, reproductive status, and 219 survival. Age-corrected weight and FEC measures were generated by fitting them as response 220 variables in linear models with age (as a categorical variable, with ages $\geq 9$ grouped together; 221 Table S5) and anthelminthic treatment as explanatory variables. Model residuals were then 222 extracted as measures of age-corrected summer weight and FEC. Reproductive status and 223 survival were also age-corrected: each was fitted as a response variable in a generalised linear 
model with a binomial distribution and age and treatment fitted as explanatory variables.

Residuals were extracted to obtain age-corrected measures of reproductive status and survival.

Variables were then standardised by dividing by one standard deviation. Our results and conclusions were unaffected by the exclusion of treated animals from the analysis.

We first explored each pathway in our SEM using separate (generalised) linear mixed-effects models using the R package 'Ime4' (Bates et al. 2015). Year and individual identity were included in each model as random effects except for spring FEC, where only year was included as a random effect since between-individual effects were negligible. We then conducted formal 'piecewise' structural equation modelling to join the multiple models into a single SEM (Shipley 2009), using the R package 'piecewiseSEM' (Lefcheck 2015). Shipley's test of dseparation was used to assess the overall fit of the model and to determine whether any paths were missing (Shipley 2009); missing paths were added into the model (Grace et al. 2015). Non-supported paths were removed from the SEM (based on AIC comparison) to improve parameter estimation of the remaining paths. After removal of non-supported paths, the model could not be improved by adding or removing any path.

\section{$241 \quad \underline{\text { Results }}$}

\section{Characterisation of the peri-parturient rise (PPR)}

243 All age-sex groups showed a PPR in spring faecal egg count (FEC) (Fig. 2). Generally, this 244 was characterised by a peak in FEC close to parturition (day 0). For juveniles, the best-fitting model grouped all individuals together $(\triangle \mathrm{AIC}$ relative to next best model $=-2$; Table $\mathrm{S} 2$; Table S6). Juveniles had consistently higher FEC than the other age groups, with a peak of 1386epg

247 (eggs per gram; 95\% CI = 1088-1759epg) on day 0 (Fig. 2A). There was marginal evidence suggesting that the best-fitting model for yearlings grouped individuals by sex $(\triangle \mathrm{AIC}=-1$; 
evidence ratio $=0.63$; Table S3; Table S7). Males had a higher peak spring FEC, 792epg (5181189epg) than females, 521epg (91-685epg; Fig. 2B). Both sexes' peak occurred on day 6.

For adults, the best-fitting model grouped individuals based on litter survival in August: (1) males; (2) non-reproducing females; (3) reproducing females with no surviving lambs; (4) reproducing females with at least one surviving lamb $(\triangle \mathrm{AIC}=-4$; Table S4; Table S8). Females with at least one surviving lamb had a higher and later peak FEC than those that reproduced but whose lambs died before weaning, but both had much higher peak than non-reproducing females. The peak FEC of females with at least one surviving lamb was 370epg (270-495epg) on day 15, whereas the peak FEC of females whose lambs died was 264epg (178-376epg) on day -5 (Fig. 2C). Non-reproducing females had the lowest spring FEC, peaking at 123epg (69194epg) on day -1 (Fig. 2C). Males had an intermediate peak FEC, 222epg (143-327epg) which occurred on day -20 (Fig. 2C).

\section{Survival costs of reproduction}

264 During the model specification stage, population density in the previous August was dropped from the SEM as its inclusion did not improve the models. The SEM of the minimal adequate models did not support two paths included in our a priori model: reproductive status $\rightarrow$ August FEC and population density $\rightarrow$ survival $(\triangle \mathrm{AIC}=-8.5)$. The final SEM adequately fitted the data (i.e., there were no missing paths; Fisher's $\mathrm{C}=8.59 ; \mathrm{P}=0.57$; Fig. 3). Reproductive status had effects on survival mediated by residual spring FEC, August weight, and August FEC. Pathways linking residual spring FEC and overwinter survival were mediated by effects of residual spring FEC on August weight and August FEC. Weight and FEC in August were also linked to survival. We also found effects of August density (year $t$ ) on August weight and 
273 August FEC, both of which influenced age-corrected survival. Table 2 shows the total influence

274 of each variable (the products of standardised predictors along each path) on survival.

275

276 Discussion

277 Using data collected from a wild population of Soay sheep, we found increased reproductive

278 allocation was associated with greater gastrointestinal nematode faecal egg count (FEC) during

279 the lambing season. Further, the association between reproduction and overwinter survival was

280 mediated by effects of reproduction on spring and summer FEC and summer body weight.

281 Overall, our work demonstrates how parasites can mediate associations between reproduction

282 and future survival.

283

284 Reproductive allocation influences FEC

285 We found the effects of sex and/or reproductive allocation on spring FEC became more apparent in adults compared to juveniles and yearlings: juvenile FEC was not influenced by sex or reproductive status; there was marginal evidence that yearling FEC was influenced by sex; and adult FEC was influenced by both. Juveniles had generally high FEC, as predicted from previous research on other wild vertebrates (Wilson et al. 1996; Isomursu et al. 2006; Hayward 2013; Watson et al. 2016) and humans (Simon et al. 2015), which suggests that

291 juveniles have not developed fully effective immune defences. Yearling males tended to have 292 higher spring FEC than females (marginal statistical support; estimate $=0.36 \pm 0.17 \mathrm{SE}, \Delta \mathrm{AIC}$ $293=-1$; evidence ratio $=0.63$ ); this result is consistent with studies from diverse species that have 294 found males to have less effective immune responses (Tschirren et al. 2003; Hayward 2013; 295 Klein \& Flanagan 2016; Watson et al. 2016). 
297 The best-supported model for adults grouped animals into four categories: males, non298 reproducing females, reproducing females with no surviving lambs, and reproducing females

299 with surviving lambs. The different patterns of FEC between females with surviving or no 300 surviving lambs suggest that lactation may play a role in these differences (Fig. 2C). Lactation 301 uses resources that could otherwise be allocated to immunity (Coop \& Kyriazakis 1999) and 302 studies on red deer (Cervus elaphus) suggest that lactation is more expensive than gestation 303 (Clutton-Brock et al. 1989; Froy et al. 2016). Moreover, experimental studies on domestic 304 sheep have shown that provisioning protein during lactation reduces FEC (Houdijk et al. 2003). 305 The number of surviving offspring that a female had did not influence the trajectory of FEC 306 changes, which could be because peak lactation is fixed (Johnson et al. 2001), or because only

307 females with the greatest resource pool produce twins (Cassinello \& Gomendio 1996; Hewison 308 \& Gaillard 2001). Another possibility is that high FEC just before lamb birth may cause ewes 309 to lose their lamb soon after birth and thus experience a decrease in FEC thereafter, while ewes 310 that keep their lamb have their FEC continue to rise (Fig. 2C). There is evidence that dairy 311 sheep treated with anthelmintic produce less milk (Fthenakis et al. 2005), but a link between 312 worm infections and lamb survival has not been demonstrated explicitly (Fthenakis et al. 2015).

313 A rise in FEC across the season was also seen in males. This is likely due to males being in 314 poor condition following the winter (Gulland \& Fox 1992), the weaker antibody responses 315 males exhibit (Hayward et al. 2014; Watson et al. 2016), and the re-emergence of larvae from 316 arrested development in spring (Langrová et al. 2008).

318 Our results agree with brood manipulation studies on birds showing that increased allocation 319 to reproduction is associated with greater parasite burdens and less effective immune responses 320 (Nordling et al. 1998; Hanssen et al. 2005; Knowles et al. 2009). Our work also largely agrees with previous work on the Soay sheep population, despite differences in the data and analyses 
used. Previous work found that FEC during the lambing season varied with age and reproductive status: young animals that failed to reproduce experienced a PPR while nonreproducing adult females did not. Further, reproducing females that successfully weaned a lamb experienced a peak in FEC after lamb birth, while those that lost their lamb had an earlier peak (Tempest 2005). Along with previous work, our findings suggest a more pronounced difference between individuals based on reproductive status in older animals, and a more general PPR in younger animals. Our study has, however, extended previous work by investigating not only the effects of sex and reproduction on FEC, but also the effects of different aspects of reproduction.

It is possible that our results could reflect variation in exposure between groups rather than reflecting a trade-off with reproduction. There is known heterogeneity in larval distribution around Village Bay (Wilson et al. 2004), and there may be differences in feeding rates between the reproductive groups of females, resulting in differences in exposure to larval parasites and influencing the patterns of FEC seen here. However, it has been shown that Soays actively avoid grazing more contaminated areas in spring and that males, barren females, and females with lambs all avoid parasite-rich vegetation to a similar degree (Hutchings et al. 2002).

339 Moreover, experimental work in domestic sheep shows that greater infective doses (i.e. increased exposure) do not result in a greater PPR (Kidane et al. 2009). Finally, new work on

341 the Soay sheep has shown that increased reproductive effort is associated with reduced 342 strongyle-specific antibody responses (Hayward et al. 2019). Therefore, it appears unlikely that

343 variation in exposure is the main driver of the variation seen in the PPR in this study. 
346 As predicted by our hypothesis of parasite-mediated reproductive costs, structural equation

347 models (SEMs) revealed that reproducing females had reduced survival, mediated by spring

348 and summer FEC and summer weight (Fig. 3). These pathways are consistent with a trade-off

349 between reproductive allocation during spring and overwinter survival, mediated by parasite

350 resistance and body weight. While previous studies in wild populations suggest that

351 reproduction incurs survival (Stearns 1992; Clutton-Brock et al. 1996; Hodges et al. 2015) and

352 immunity costs (Festa-Bianchet 1989; Richner et al. 1995; Nordling et al. 1998; Knowles et

353 al. 2009; Graham et al. 2010; Hayward et al. 2014), and that parasites influence survival

354 (Hanssen et al. 2005; la Puente et al. 2010; Hayward et al. 2011), we have explicitly quantified

355 the pathways through which reproduction influences survival, via associations between

356 reproduction, FEC and body weight (Fig. 3).

357

358 Spring FEC was positively associated with August FEC (Fig. 3). This could arise via three non-

359 mutually exclusive mechanisms: effects of reproduction on FEC persisted across several

360 months; reproduction and infection in spring lead to reduced parasite resistance in summer;

361 and/or FEC is repeatable across seasons (Coltman et al. 2001). Increased August FEC was

362 linked to reduced overwinter survival, as expected from previous work in this population

363 (Gulland \& Fox 1992; Hayward et al. 2011). Reproductive allocation was also linked to

364 reduced survival through the association between spring FEC and August body weight.

365 Previous studies showing such explicit support for any mediators of a reproduction-survival

366 trade-off are rare (Hamel et al. 2010). Work on tree swallows (Tachycineta bicolor) showed

367 that experimentally-increased brood size was associated with reduced antibody responses to

368 sheep red blood cell (SRBC) antigen, and that individuals that survived to the next season had

369 higher SRBC responses (Ardia et al. 2003). However, SRBC responses may not reflect 
resistance to prevalent parasites, and this analysis did not quantify how resistance mediates the association between reproduction and survival.

373 A major advantage of using SEMs is that if there were other important mediating factors between reproduction and survival, Shipley's test would indicate a missing path between reproduction and survival as missing paths can not only indicate a direct association between variables, but may also reflect all direct and indirect pathways not otherwise modelled (Shipley 2009; Lefcheck 2015). Shipley's test estimates that in our model (Fig. 3), the direct pathway between reproduction and survival would have an estimate of $0.0053 \pm 0.04$, but that this pathway was not statistically supported. In our case, the direct and indirect paths are of the same order of magnitude, which is difficult to interpret considering the direct effect was not statistically supported. Considering this, the most conservative interpretation of our SEM is that at least as much variation in survival is explained by the mediating influence of FEC as is explained by all other direct and indirect factors flowing from reproduction combined. However, as the missing direct association was not detected, we are confident that there are no important missing mediators between reproduction and survival. Therefore, the important mediating factors of survival costs of reproduction in this population appear to be FEC and body weight, or their close correlates.

In our a priori path diagram, weight is conceived as a potentially mediating link between

390 reproduction and survival because we expect that costs of reproduction involve reduced storage

391 of nutritional reserves. However, we also acknowledge that innate variation between

392 individuals that are not directly caused by reproduction ('condition' in the broad sense) might 
cause differences in weight that affect survival. In that sense, variation in weight is not merely

a consequence of prior reproduction, but probably reflects unmeasured variation between individuals that we cannot disentangle from weight in our analysis. One direction for future research could involve modelling the latent causes of weight variation, including reproduction and infection. A recent study on the Soay sheep showed that variation in plasma proteins, independently of body weight and potentially reflecting variation in acquisition of resources, predicted over winter survival (Garnier et al. 2017). Assessing how reproductive effort is associated with such nutritional markers could therefore provide more insight into the link between reproduction, weight, and survival. The nature of the association between August weight and August FEC also represented a challenge, since these are measured simultaneously and the association is likely mutually antagonistic (Koski \& Scott 2001; Beldomenico et al. 2008). In our SEM, we suggested that weight influences FEC, which we believed to be the most plausible direction for the association: weight should be more stable than FEC, which can fluctuate greatly within a short time-period. Body weight also has higher repeatability and

407 heritability than FEC (Coltman et al. 2001) and although body weight may fluctuate, due to 408 bladder fullness or a wet fleece, these fluctuations are minor compared to the larger fluctuations in FEC (Pollott et al. 2004). A final compromise made in our analyses was the decision to perform our SEMs with parameters derived from GAMMs. The caveats of performing

411 statistical analyses on model estimates (e.g. best linear unbiased predictors, BLUPs) are well-

412 known (Hadfield et al. 2010); for example, the error with which model estimates are generated

413 are not carried forward. Faced with the challenge of condensing multiple FEC values collected

414 during spring from one female collected in one year into a single value, while accounting for

415 age and other factors, our approach was the only viable option. The fact that our results reliably 416 reflect prior knowledge of the system gives us confidence that our SEM is effective at 417 representing the pathways linking reproduction, parasites, and survival. 
419 In this study, we found that increased allocation to reproduction was associated with increased 420 FEC during late pregnancy and early lactation. We demonstrated that the negative relationship between reproductive allocation and survival is mediated through effects of reproduction on FEC and body weight. The results of our study have several far-reaching implications. First, like previous studies (Festa-Bianchet 1989; Richner et al. 1995; Ardia et al. 2003; Hanssen et al. 2005; Graham et al. 2010; la Puente et al. 2010; Mills et al. 2010; East et al. 2015), we have shown that reproduction is associated with increased FEC/reduced immune responses, and that these are associated with reduced survival. However, we have also shown explicit links between reproduction, parasites, and survival in a wild system, providing support for a key theory of maintenance of variation in resistance (Sheldon \& Verhulst 1996; Rolff \& Siva-Jothy 2003; Graham et al. 2011). Second, the trade-off between reproduction and survival is fundamental, explaining variation in ageing, mating strategies, and sexual traits (Rowe \& Houle 1996; Blomquist 2009; Lemaître et al. 2015). Our results therefore have broad implications for how trade-offs can shape variation within populations. Finally, as the role of parasites in regulating populations is well-known (Anderson \& May 1978; Hudson et al. 1992), we demonstrate that reproductive costs could play a role in regulating populations through the effects that they have on parasites. Overall, our work has explicitly quantified the survival costs of reproduction mediated through FEC and the effects of FEC on body weight, providing support for the theory of parasite-mediated reproductive costs. 
443 We thank the National Trust for Scotland for permission to work on St Kilda and QinetiQ and 444 Elior for logistics and other support on the island. We are especially grateful to Dan Nussey 445 and Andrea Graham for insightful comments on an earlier draft of the manuscript and to 446 Jonathan Chase, Jean-Michel Gaillard and five reviewers for highly constructive comments 447 which greatly improved the manuscript. We are indebted to the many people who have 448 collected spring faecal egg count data over the years, particularly Frances Gulland and Louisa 449 Tempest. We are grateful to all project members and many volunteers who have helped with 450 field work on the island and all those who have contributed to keeping the project going over 451 many years, including T. Clutton-Brock, M. Crawley, S. Albon, L. Kruuk, T. Coulson and D. 452 Nussey. The long-term project on St Kilda, including field assistant JGP, has been largely 453 funded by the UK Natural Environment Research Council. JAL and LFB were both supported by the University of Stirling. ADH has received support from a University of Stirling Impact Research Fellowship and a Moredun Foundation Research Fellowship.

456

457

458

459

460

461

462

463

464

465

466 
$\underline{\text { References }}$

468 1.Anderson, R.M. \& May, R.M. (1978). Regulation and Stability of Host-Parasite Population 469 Interactions: I. Regulatory Processes. J. Anim. Ecol., 47, 219-247

470

2.Ardia, D.R., Schat, K.A. \& Winkler, D.W. (2003). Reproductive effort reduces long-term 472 immune function in breeding tree swallows (Tachycineta bicolor). Proc. R. Soc. B, 270, 473 $1679-1683$

474

475

3. Armour, J., Jarrett, W.F.H., Jennings, F.W. (1996) Experimental Ostertagia circumcincta 476 infections in sheep: development and pathogenesis of a single infection. American Journal of Veterinary Research 27, 1267-1278

478

479

4.Bates, D., Maechler, M., Bolker, B. \& Walker, S. (2015). Fitting linear mixed-effects 480 models using lme4. J. Stat. Softw., 67, 1-48

481

482

5.Beldomenico, P.M., Telfer, S., Gebert, S., Lukomski, L., Bennett, M. \& Begon, M. (2008).

483

Poor condition and infection: a vicious circle in natural populations. Proc. R. Soc. B, 275,

484 $1753-1759$

485

486

6.Blomquist, G.E. (2009). Trade-off between age of first reproduction and survival in a

487 female primate. Biol. Lett., 5, 339-42

488

489

7.Boyd, H.E.G. (1999). The Early Development of Parasitism in Soay Sheep on St Kilda,

490 PhD Thesis, University of Cambridge

491 
492 8.Burnham, K.. \& Anderson, D.R. (2002). Model Selection and Multimodel Inference.

493 Springer-Verlag, New York

494

495

9.Cassinello, J. \& Gomendio, M. (1996). Adaptive variation in litter size and sex ratio at birth

496 in a sexually dimorphic ungulate. Proc. R. Soc. B, 263, 1461-1466

497

498

10.Clutton-Brock, T.H., Albon, S.D. \& Guinness, F.E. (1989). Fitness costs of gestation and

499

lactation in wild mammals. Nature, 337, 260-262

500

501

11.Clutton-Brock, T.H. \& Pemberton, J.M. (Eds.). (2004). Soay Sheep: Dynamics and

502

Selection in an Island Population. 1st edn. Cambridge University Press, Cambridge

503

504

12.Clutton-Brock, T.H., Price, O.F., Albon, S.D. \& Jewell, P.A. (1991). Persistent instability

505

and population regulation in Soay sheep. J. Anim. Ecol., 60, 593-608

506

507

13.Clutton-Brock, T.H., Price, O.F., Albon, S.D. \& Jewell, P.A. (1992). Early development

508

and population fluctuations in Soay sheep. J. Anim. Ecol., 61, 381-396

509

510

14.Clutton-Brock, T.H., Stevenson, I.R., Marrow, P., MacColl, A.D., Houston, A.I. \&

McNamara, J.M. (1996). Population fluctuations, reproductive costs and life-history tactics in

512 female Soay sheep. J. Anim. Ecol., 65, 675-689

513

514 15.Coltman, D.W., Pilkington, J.G., Kruuk, L.E.B., Wilson, K. \& Pemberton, J.M. (2001).

515 Positive Genetic Correlation between Parasite Resistance and Body Size in a Free-Living

516 Ungulate Population. Evolution, 55, 2116-2125 
518 16.Coop, R.L. \& Kyriazakis, I. (1999). Nutrition - parasite interaction. Vet. Parasitol., 84, $519 \quad 187-204$

520

521 17.Coulson, T., Catchpole, E.A., Albon, S.D., Morgan, B.J.T., Pemberton, J.M., Clutton-

522 Brock, T.H., et al. (2001). Age, Sex, Density, Winter Weather, and Population Crashes in

523 Soay Sheep. Science, 292, 1528-1531

524

525 18.Craig, B.H., Pilkington, J.G. \& Pemberton, J.M. (2006). Gastrointestinal nematode species 526 burdens and host mortality in a feral sheep population. Parasitology, 133, 485-96

527

528

19.Descamps, S., Boutin, S., McAdam, A.G., Berteaux, D. \& Gaillard, J.-M. (2009). Survival 529 costs of reproduction vary with age in North American red squirrels. Proc. R. Soc. B, 276,

530 $1129-35$

531

532

20.East, M., Otto, E., Helms, J., Theirer, D., Cable, J. \& Hofer, H. (2015). Does lactation lead 533 to resource allocation trade-offs in the spotted hyaena? Behav. Ecol. Sociobiol., 69, 805-814 534

21.Festa-Bianchet, M. (1989). Individual differences, parasites, and the costs of reproduction

536 for bighorn ewes (Ovis canadensis). J. Anim. Ecol., 58, 785-795

537

538

22.Froy, H., Walling, C.A., Pemberton, J.M., Clutton-Brock, T.H. \& Kruuk, L.E.B. (2016).

Relative costs of offspring sex and offspring survival in a polygynous mammal. Biol. Lett.,

540

12, 20160417 
23.Fthenakis, G.C., Mavrogianni, V.S., Gallidis, E. \& Papadopoulos, E. (2015). Interactions between parasitic infections and reproductive efficiency in sheep. Vet. Parasitol., 208, 56-66

24. Fthenakis, G.C., Papadopoulos, E., Himonas, C. (2005) Effects of Three Anthelmintic Regimes on Milk Yield of Ewes and Growth of Lambs. J. Vet. Med. 52, 78-82

25.Garnier, R., Cheung, C.K., Watt, K.A., Pilkington, J.G., Pemberton, J.M. \& Graham, A.L. (2017). Joint associations of blood plasma proteins with overwinter survival of a large mammal. Ecol. Lett., 20, 175-183

551

26.Grace, J.B., Adler, P.B., Harpole, S.W., Borer, E.T. \& Seabloom, E.W. (2014). Causal networks clarify productivity - richness interrelations, bivariate plots do not. Funct. Ecol., 28, $787-798$

27.Grace, J.B., Scheiner, S.M. \& Schoolmaster, D.R. (2015). Structural equation modeling: building and evaluating causal models. In: Ecological Statistics: Contemporary Theory and Application (eds. Fox, G.A., Negrete-Yankelvich, S. \& Sosa, V.J.). Oxford University Press, Oxford, pp. 168-199

28.Graham, A.L., Hayward, A.D., Watt, K.A., Pilkington, J.G., Pemberton, J.M. \& Nussey, D.H. (2010). Fitness correlates of heritable variation in antibody responsiveness in a wild mammal. Science, 330, 662-664 performance and steroid hormone profiles of pregnant versus nonpregnant cottonmouth 
30.Gulland, F.M. (1992). The role of nematode parasites in Soay sheep (Ovis aries L.)

570 mortality during a population crash. Parasitology, 105, 493-503

571

572

31.Gulland, F.M., Albon, S.D., Pemberton, J.M., Moorcroft, P.R. \& Clutton-Brock, T.H.

573

(1993). Parasite-associated polymorphism in a cyclic ungulate population. Proc. R. Soc. B,

574

$254,7-13$

575

576

32.Gulland, F.M. \& Fox, M. (1992). Epidemiology of nematode infections of Soay sheep.

Parasitology, 105, 481-492

578

579

33.Hadfield, J.D., Wilson, A.J., Garant, D., Sheldon, B.C. \& Kruuk, L.E.B. (2010). The misuse of BLUP in ecology and evolution. Am. Nat., 175, 116-125

581

582

34.Hamel, S., Gaillard, J.M., Yoccoz, N.G., Loison, A., Bonenfant, C. \& Descamps, S. (2010). Fitness costs of reproduction depend on life speed: Empirical evidence from mammalian populations. Ecol. Lett., 13, 915-935

585

35.Hanssen, S.A., Hasselquist, D., Folstad, I. \& Erikstad, K.E. (2005). Cost of reproduction

587 in a long-lived bird: incubation effort reduces immune function and future reproduction.

$588 \quad$ Proc. R. Soc. B, 272, 979-1082

590 36.Hayward, A.D. (2013). Causes and consequences of intra- and inter-host heterogeneity in

591 defence against nematodes. Parasite Immunol., 35, 362-373 
593 37.Hayward, A.D., Garnier, R., Watt, K.A., Pilkington, J.G., Grenfell, B.T., Matthews, J.B., 594 et al. (2014). Heritable, heterogeneous, and costly resistance of sheep against nematodes and 595 potential feedbacks to epidemiological dynamics. Am. Nat., 184, S58-76

596

597 38.Hayward, A.D., Pemberton, J.M., Berenos, C., Wilson, A.J., Pilkington, J.G. \& Kruuk, 598 L.E.B. (2018). Evidence for selection-by-environment but not genotype-by-environment interactions for fitness-related traits in a wild mammal population. Genetics, 208, 349-364

600

601

39.Hayward, A.D., Pilkington, J.G., Wilson, K., McNeilly, T.N. \& Watt, K.A. (2019).

602 Reproductive effort influences intra-seasonal variation in parasite-specific antibody responses 603 in wild Soay sheep. Funct. Ecol., In Press (accepted)

604

605

40.Hayward, A.D., Wilson, A.J., Pilkington, J.G., Clutton-Brock, T.H., Pemberton, J.M. \& 606 Kruuk, L.E.B. (2011). Natural selection on a measure of parasite resistance varies across ages and environmental conditions in a wild mammal. J. Evol. Biol., 24, 1664-1676

608

609

41.Hewison, A.J.M. \& Gaillard, J.M. (2001). Phenotypic quality and senescence affect different components of reproductive output in roe deer. J. Anim. Ecol., 70, 600-608

611

612 42.Hodges, C.J., Bowers, E.K., Thompson, C.F. \& Sakaluk, S.K. (2015). Cascading costs of

613 reproduction in female house wrens induced to lay larger clutches. J. Evol. Biol., 28, 13836141393

615

616 43.Houdijk, J.G., Kyriazakis, I., Jackson, F., Huntley, J.F. \& Coop, R.L. (2003). Is the 
617 allocation of metabolisable protein prioritised to milk production rather than to immune

618 functions in Teladorsagia circumcincta-infected lactating ewes? Int. J. Parasitol., 33, 327-

$619 \quad 338$

620

621 44.Hudson, P.J., Newborn, D. \& Dobson, A.P. (1992). Regulation and stability of a free-

622 living host-parasite system: Trichostrongylus tenuis in red grouse. I. Monitoring and parasite 623 reduction experiments. J. Anim. Ecol., 61, 477-486

624

625

45.Hutchings, M.R., Milner, J.M., Gordon, I.J., Kyriazakis, I. \& Jackson, F. (2002). Grazing 626 decisions of Soay sheep, Ovis aries, on St Kilda: a consequence of parasite distribution?

627 Oikos, 96, 235-244

628

629

46.Isomursu, M., Rätti, O., Helle, P. \& Hollmén, T. (2006). Sex and age influence intestinal 630 parasite burden in three boreal grouse species. J. Avian Biol., 37, 516-522

631

632

47.Johnson, M.S., Thomson, S.C. \& Speakman, J.R. (2001). Limits to sustained energy

633

intake, lactation in the laboratory mouse Mus musculus. J. Exp. Biol., 204, 1925-1935

634

635

48.Katoch, R., Yadav, A., Godara, R., Khajuria, J.K., Borkataki, S. \& Sodhi, S.S. (2012).

636 Prevalence and impact of gastrointestinal helminths on body weight gain in backyard

637 chickens in subtropical and humid zone of Jammu, India. J. Parasit. Dis., 36, 49-52

638

639 49.Kidane, A., Houdijk, J.G., Tolkamp, B.J., Athanasiadou, S. \& Kyriazakis, I. (2009).

640 Consequences of infection pressure and protein nutrition on periparturient resistance to

641 Teladorsagia circumcincta and performance in ewes. Vet. Parasitol., 165, 78-87 
643 50.Klein, S.L. \& Flanagan, K.L. (2016). Sex differences in immune responses. Nat. Rev.

644 Immunol., 16, 626-638

645

646 51.Knowles, S., Nakagawa, S. \& Sheldon, B.C. (2009). Elevated reproductive effort

647 increases blood parasitaemia and decreases immune function in birds: A meta-regression

648 approach. Funct. Ecol., 23, 405-415

649

650 52.Koski, K.G. \& Scott, M.E. (2001). Gastrointestinal nematodes, nutrition and immunity:

651 Breaking the Negative Spiral. Annu. Rev. Nutr., 21, 297-321

652

653 53.Langrová, I., Makovcová, K., Vadlejch, J., Jankovská, I., Petrtýl, M., Fechtner, J., et al.

654 (2008). Arrested development of sheep strongyles: onset and resumption under field

655 conditions of Central Europe. Parasitol. Res., 103, 387-392

656

657

54.Lefcheck, J.S. (2015). piecewiseSEM: Piecewise structural equation modelling in $\mathrm{r}$ for

658

ecology, evolution, and systematics. Methods Ecol. Evol., 7, 573-579

659

660 55.Lemaître, J.-F., Berger, V., Bonenfant, C., Douhard, M., Gamelon, M., Plard, F., et al.

661 (2015). Early-late life trade-offs and the evolution of ageing in the wild. Proc. R. Soc. B, 282,

66220150209

663

664 56.Lindenmayer, D.B., Likens, G.E., Andersen, A., Bowman, D., Bull, C.M., Burns, E., et al.

665 (2012). Value of long-term ecological studies. Austral Ecol., 37, 745-757

666 
667 57.Lloyd, S. (1983). Effect of pregnancy and lactation upon infection. Vet. Immunol.

668 Immunopathol., 4, 153-176

669

670 58.Mills, S.C., Grapputo, A., Jokinen, I., Koskela, E., Mappes, T. \& Poikonen, T. (2010).

671 Fitness trade-offs mediated by immunosuppression costs in a small mammal. Evolution, 64,

$672 \quad 166-179$

673

674 59.Milner, J.M., Elston, D.A. \& Albon, S.D. (1999). Estimating the contribution of

675 population density and climatic fluctuations to interannual variation in survival of Soay

676 sheep. J. Anim. Ecol., 68, 1235-1247

677

678

60.van Noordwijk, A. \& de Jong, G. (1986). Acquisition and allocation of resources - their

679

influence on variation in life-history tactics. Am. Nat., 128, 137-142

680

681

61.Nordling, D., Andersson, M.S., Zohari, S. \& Lars, G. (1998). Reproductive effort reduces

682

specific immune response and parasite resistance. Proc. R. Soc. B, 265, 1291-1298

683

684

62.Pelletier, F., Page, K.A., Ostiguy, T., Festa-Bianchet, M. \& Lundberg, P. (2005). Fecal

685

counts of lungworm larvae and reproductive effort in bighorn sheep, Ovis canadensis. Oikos,

$686110,473-480$

687

688 63.Penn, D.J. \& Smith, K.R. (2007). Differential fitness costs of reproduction between the

689 sexes. Proc. Natl. Acad. Sci. USA., 104, 553-8

690

691 64.Pollott, G.E., Karlsson, L.J.E., Eady, S. \& Greefft, J.C. (2004). Genetic parameters for 
692 indicators of host resistance to parasites from weaning to hogget age in Merino sheep. $J$.

693 Anim. Sci., 82, 2852-2864

694

695 65.la Puente, J.M.J., Merino, S., Tomas, G., Moreno, J., Morales, J., Lobato, E., et al. (2010).

696 The blood parasite Haemoproteus reduces survival in a wild bird: a medication experiment.

697 Biol. Lett., 6, 663-665

698

699

66.R Core Team. (2018). R: A language and environment for statistical computing.

700

701

67.Richner, H., Christe, P. \& Oppliger, A. (1995). Paternal investment affects prevalence of

702

malaria. Proc. Natl. Acad. Sci. USA, 92, 1192-1194

703

704

68.Rolff, J. \& Siva-Jothy, M.T. (2003). Invertebrate Ecological Immunology. Science, 301,

705

$472-475$

706

707

69.Rowe, L. \& Houle, D. (1996). The Lek Paradox and the Capture of Genetic Variance by

708

Condition Dependent Traits. Proc. R. Soc. B, 263, 1415-1421

709

710

70.Sheldon, B.C. \& Verhulst, S. (1996). Ecological immunology: Costly parasite defences

711 and trade-offs in evolutionary ecology. Trends Ecol. Evol., 11, 317-321

712

713 71.Shipley, B. (2009). Confirmatory path analysis in a generalized multilevel context.

714 Ecology, 90, 363-368

715

716 72.Simon, A.K., Hollander, G.A. \& McMichael, A. (2015). Evolution of the immune system 
in humans from infancy to old age. Proc. R. Soc. B, 282, 20143085

718

719

73.Stearns, S.C. (1992). Trade-offs. In: The Evolution of Life Histories. 1st edn. Oxford

720

University Press, Oxford, pp. 72-90

721

722

74.Tavecchia, G., Coulson, T., Morgan, B.J.T., Pemberton, J.M., Pilkington, J.G., Gulland, 723

F.M.D., et al. (2005). Predictors of reproductive cost in female Soay sheep. J. Anim. Ecol.,

724

$74,201-213$

725

726

75.Tempest, L.J. (2005). Parasites and the cost of reproduction in Soay sheep, PhD Thesis.

727

University of Stirling

728

729

76.Tschirren, B., Fitze, P.S. \& Richner, H. (2003). Sexual dimorphism in susceptibility to

730

parasites and cell-mediated immunity in great tit nestlings. J. Anim. Ecol., 72, 839-845

731

732

77.Watson, M.J. (2013) What drives population-level effects of parasites? Meta-analysis

733

meets life-history. Int. J. Parasitol. Parasites Wildl. 2, 190-196

734

735

78.Watson, R.L., McNeilly, T.N., Watt, K.A., Pemberton, J.M., Pilkington, J.G., Waterfall,

M., et al. (2016). Cellular and humoral immunity in a wild mammal: Variation with age \&

737

sex and association with overwinter survival. Ecol. Evol., 6, 8695-8705

738

739

79.Williams, G.C. (1966). Natural selection, the cost of reproduction and a refinement of

740

Lack's principle. Am. Nat., 100, 687-690

741 
742 80.Wilson, K., Grenfell, B.T., Pilkington, J.G., Boyd, G. \& Gulland, F.M.D. (2004). Parasites

743 and their impact. In: Soay Sheep: Dynamics and Selection in an Island Population (eds.

744 Clutton-Brock, T.H. \& Pemberton, J.M.). Cambridge University Press, Cambridge, pp. 113$745 \quad 165$

746

747 81.Wilson, K., Grenfell, B.T. \& Shaw, D.J. (1996). Analysis of aggregated parasite

748 distributions: a comparison of methods. Funct. Ecol., 10, 592-601

749

750 82.Wood, S. \& Scheipl, F. (2017). gamm4: Generalized Additive Mixed Models using

751 "mgcv" and "lme4". R package version 0.2-5

752

753

754

755

756

757

758

759

760

761

762

763

764

765

766 
Table 1. Response and explanatory variables included in structural equation model (SEM) analysis, justified with published evidence supporting each association.

\begin{tabular}{clll} 
Response Variable & Explanatory Variables & Sign of Relationship & Reference \\
\hline Reproductive Status & Previous Density & Negative & (Clutton-Brock et al. 1992) \\
\hline Spring FEC & Previous Density & Positive & (Gulland \& Fox 1992) \\
& Reproductive Status & Positive & (Wilson et al. 2004) \\
\hline August Weight & Reproductive Status & Negative & (Clutton-Brock et al. 1996) \\
& Spring FEC & Negative & (Gulland 1992) \\
& August Density & Negative & (Milner et al. 1999b) \\
& Reproductive Status & Positive & (Wilson et al. 2004) \\
& Spring FEC & Positive & (Coltman et al. 2001) \\
& August Weight & Negative & (Coltman et al. 2001) \\
& August Density & Positive & (Gulland \& Fox 1992)
\end{tabular}

767

768

769

770

771

772

773

774

775

776

777

778 
Table 2. The total influence of each variable (the products of standardised coefficients along each path) shown in Figure 3, on the probability of overwinter survival.

Path

\section{Standardised Path}

\section{Estimate}

\begin{tabular}{lc}
\hline Reproductive Status $\rightarrow$ August Weight $\rightarrow$ Survival & -0.0168 \\
Reproductive Status $\rightarrow$ August Weight $\rightarrow$ August FEC $\rightarrow$ Survival & -0.0012 \\
Reproductive Status $\rightarrow$ Spring FEC $\rightarrow$ August FEC $\rightarrow$ Survival & -0.0044 \\
Reproductive Status $\rightarrow$ Spring FEC $\rightarrow$ August Weight $\rightarrow$ Survival & \\
Reproductive Status $\rightarrow$ Spring FEC $\rightarrow$ August Weight $\rightarrow$ August FEC $\rightarrow$ Survival & -0.0033 \\
Spring FEC $\rightarrow$ August Weight $\rightarrow$ Survival & -0.0002 \\
Spring FEC $\rightarrow$ August Weight $\rightarrow$ August FEC $\rightarrow$ Survival & -0.0252 \\
August Weight $\rightarrow$ Survival & -0.0018 \\
August Weight $\rightarrow$ August FEC $\rightarrow$ Survival & 0.1400 \\
August FEC $\rightarrow$ Survival & 0.0100 \\
August Density $\rightarrow$ August FEC $\rightarrow$ Survival & -0.1400 \\
August Density $\rightarrow$ August Weight $\rightarrow$ Survival & -0.0140 \\
August Density $\rightarrow$ August Weight $\rightarrow$ August FEC $\rightarrow$ Survival & -0.0406 \\
\hline
\end{tabular}


790

791 Figure 1. A priori structural equation model (SEM) based on decades of research on the Soay 792 sheep population. Associations are depicted for female sheep only. Variables are temporally 793 separated over two years. Reproductive status is based on whether or not the female gave birth 794 in spring.

795

796 Figure 2. Comparison of change in strongyle FEC over a 99-day period during the lambing 797 season, analysed using generalised additive mixed-effects models (GAMMs; Tables S2-S4).

798 (A) The best-fitting model for juveniles grouped all individuals; (B) the best-fitting model for 799 yearlings grouped individuals by sex; $(\mathbf{C})$ the best-fitting model for adults grouped individuals 800 by lamb survival. Panels on the left show predictions on the log-transformed scale (the scale at 801 which data were analysed), with lines showing model estimates, shaded areas indicating $\pm 1 \mathrm{SE}$ 802 and points showing raw data. On the right, predictions are back-transformed onto the original 803 scale. Raw data are not shown on the back-transformed plots for clarity of viewing and ease of 804 interpretation.

805

806 Figure 3. Our final structural equation model (SEM) showing downstream impacts of 807 reproduction on future fitness (overwinter survival). Values on arrows and arrow widths 808 indicate standardised path coefficients with standard errors in parentheses. All variables were 809 standardised by dividing by one standard deviation.

810 


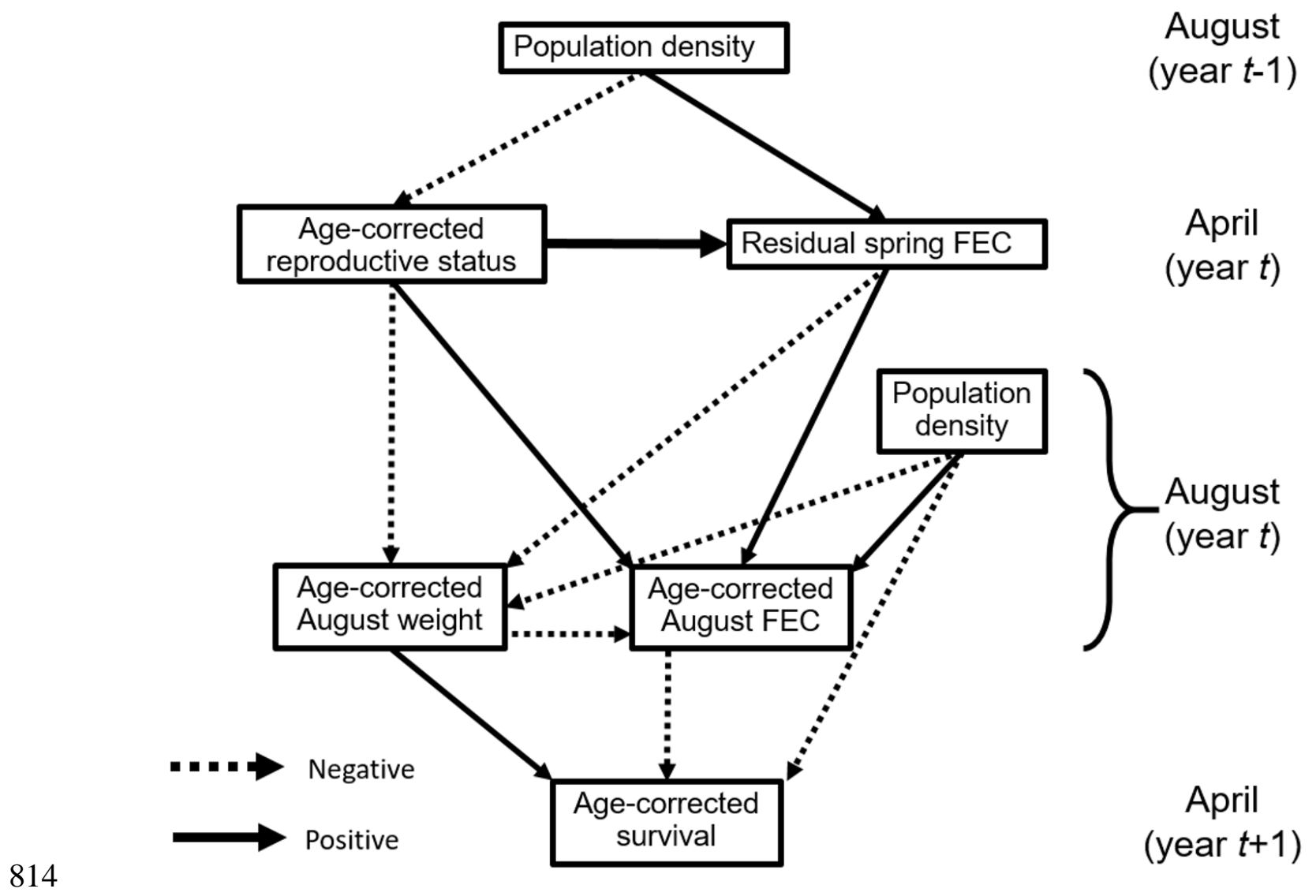



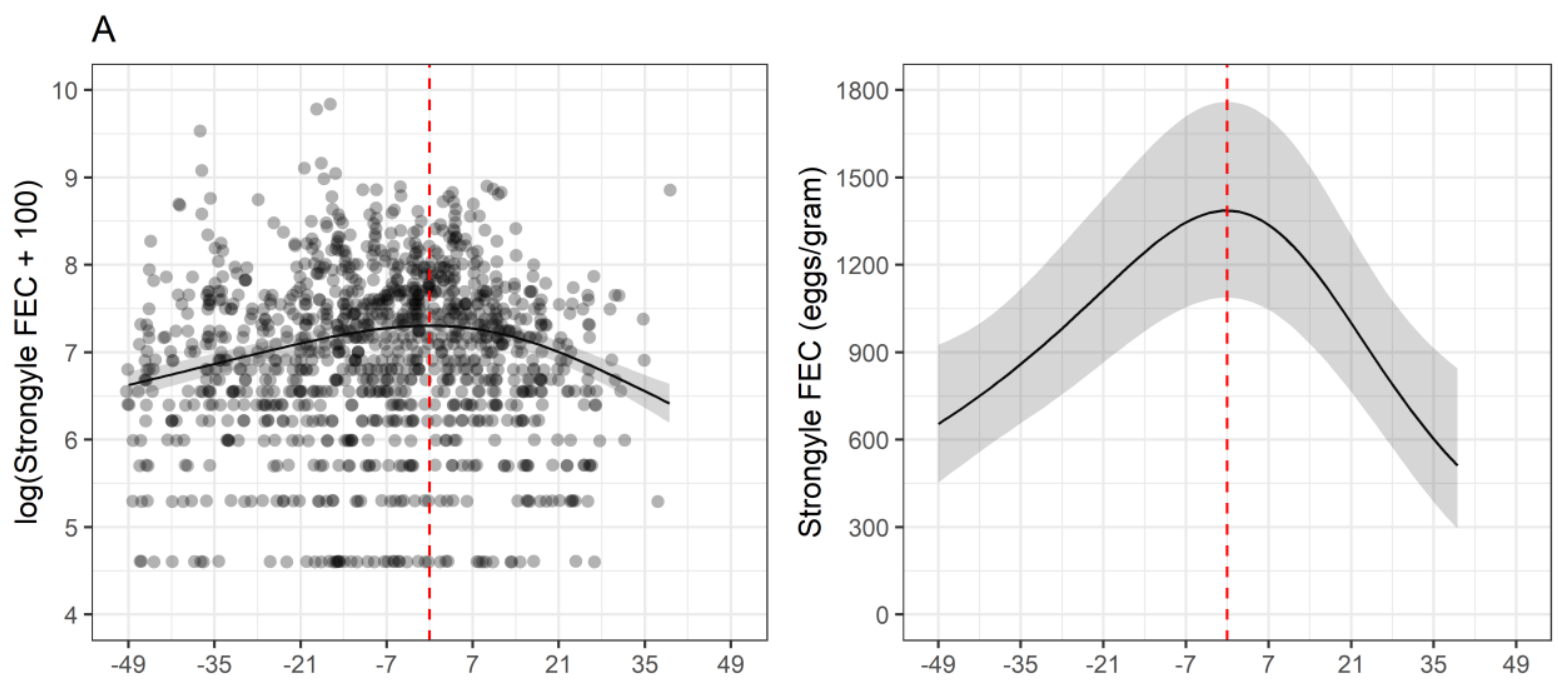

\section{B}
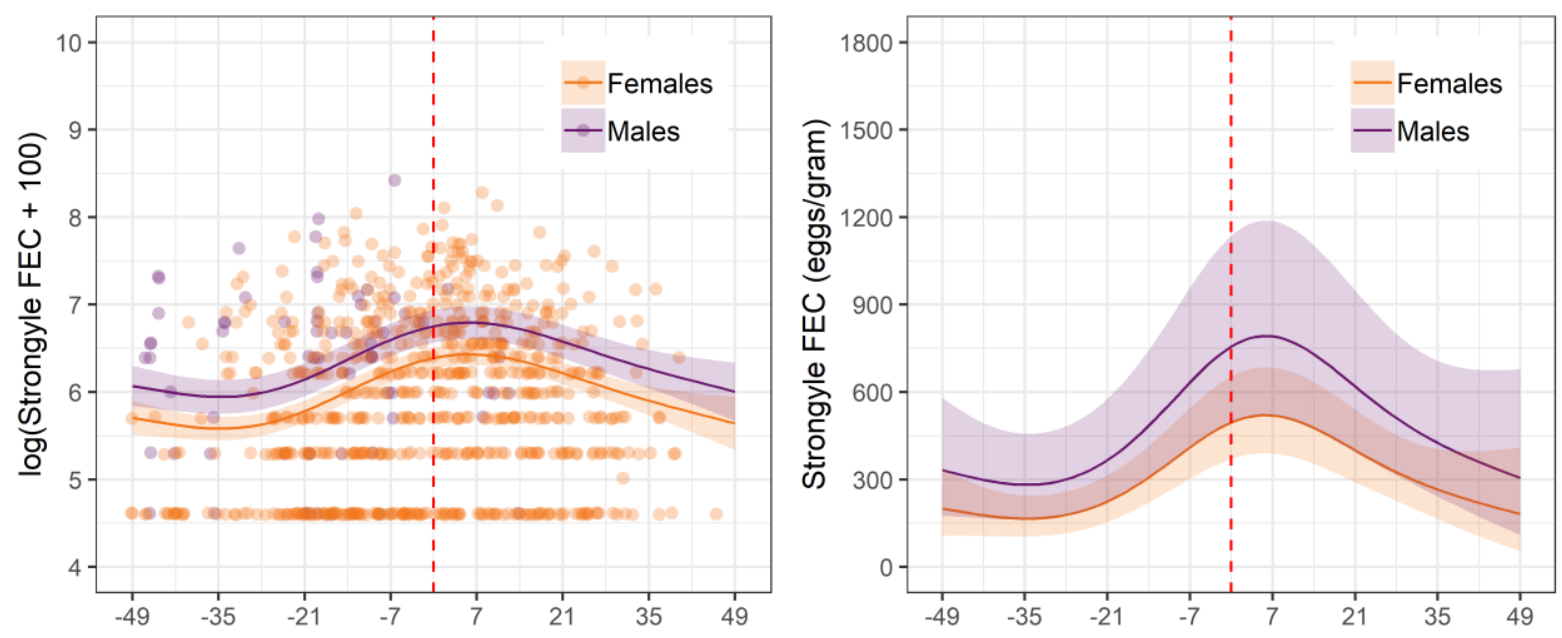

\section{C}
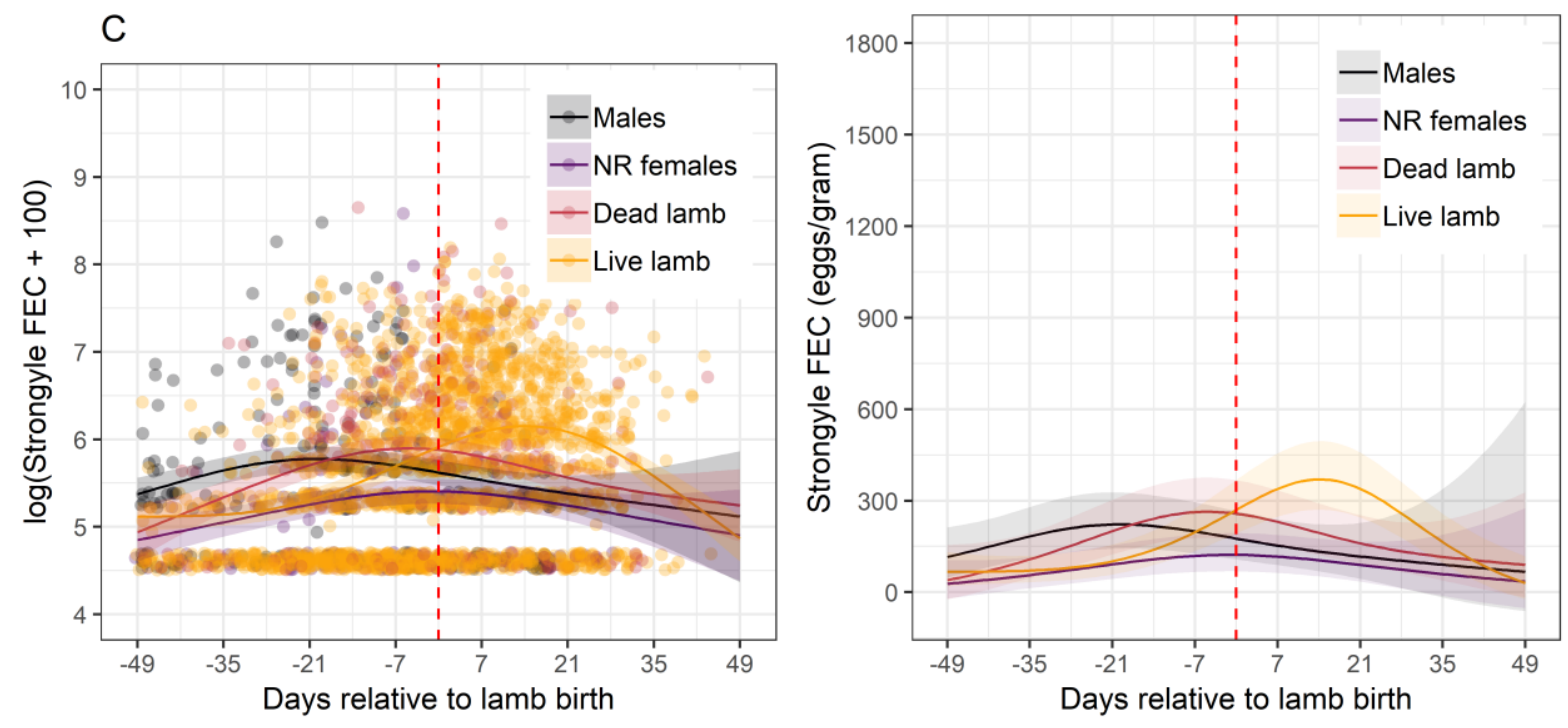

816 


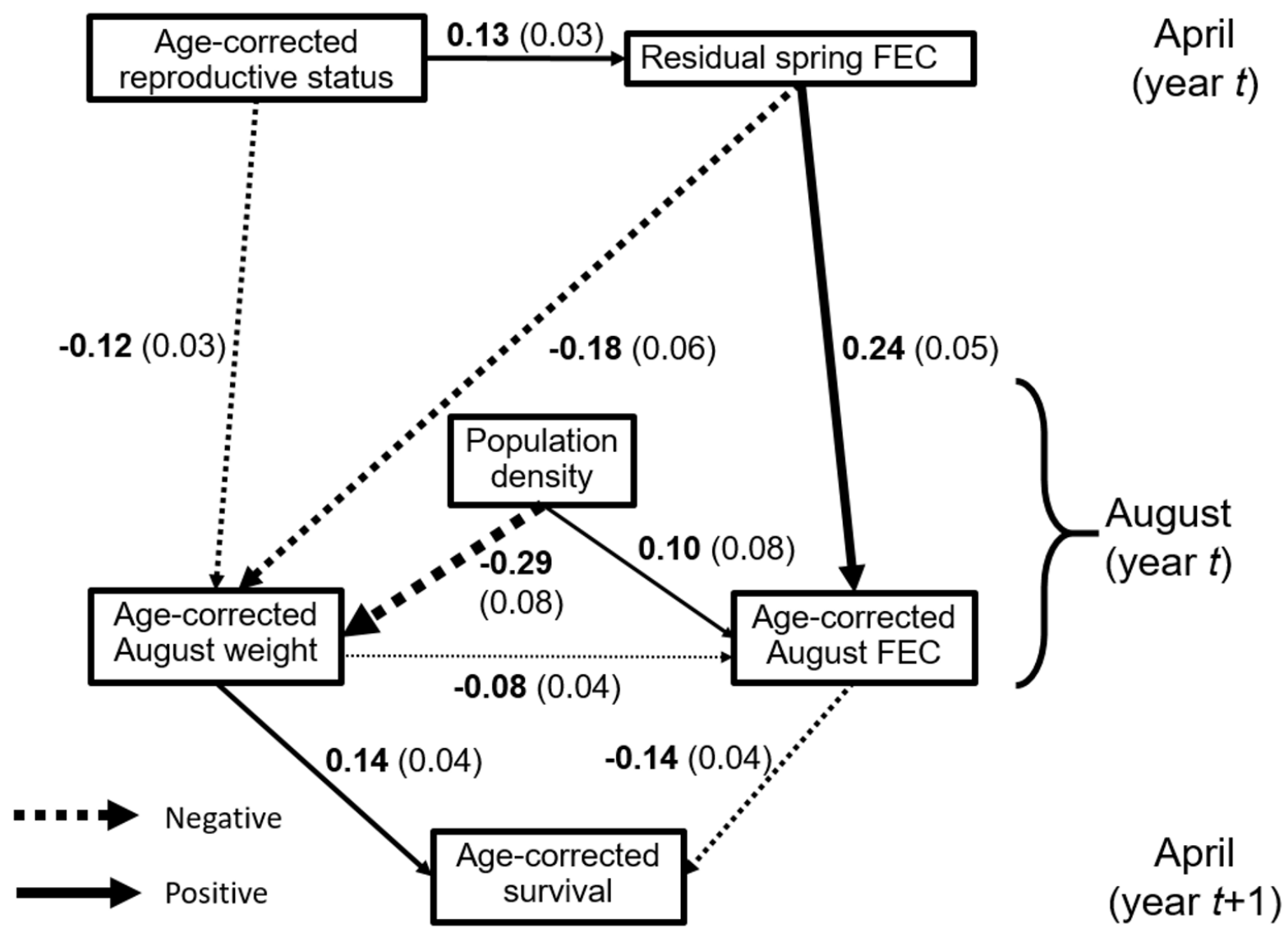

